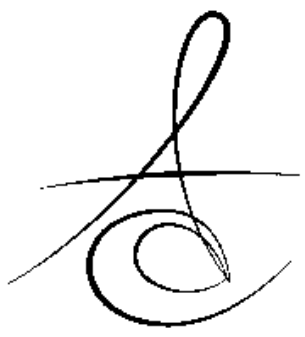

\section{ANTERİOR ÇAPRAZ KAPANIŞLI OLGUDA ÇOKLU DENTAL TRAVMA: İKİ YIL TAKİPLI OLGU RAPORU}

\section{MULTIPLE DENTAL TRAUMA IN CASE ANTERIOR CROSSBİTE: TWO YEARS FOLLOW-UP IN CASE REPORT ${ }^{*}$}

\author{
Dt. Esra KARAALİoĞLU*
}

Prof. Dr. Nurhan ÖZTAŞ*

\section{ÖZET}

Bu olgu raporunda; anterior çapraz kapanışı bulunan hastada intrüzyon ve ekstrüzyonun birlikte görüldüğü travmanın tedavisi sunulmaktadır.

8 yaşında kız hasta, Gazi Üniversitesi Diş Hekimliği Fakültesi Pedodonti Kliniği'ne kaydıraktan düşmeye bağlı travma hikayesi ile başvurdu. Hastanın 11 numaralı dişinde intrüzyon, 21 numaralı dişinde ekstrüzyon ve ön çapraz kapanış varlığı tespit edildi. Çoklu travmanın tedavi planlamasında kök uçları açık olan 11'in re-erüpsüyonu, 21'in yerine yerleştirilmesi ve 3 hafta splint yapılmasına karar verildi. 21 numaralı dişin 6. Ay kontrolünde vitalite kaybı ve renkleşmeye bağı apeksifikasyon tedavisi yapılmasına karar verildi. Hastanın 3 aylık periodlarla 24 ay takibi yapıldı.

İntrüze diş, 12. ay kontrolünde vitalitesini koruyup çapraz kapanıştan çıkarak re-erüpte oldu. Ekstrüze dişin apeksifikasyon sonrasında 12, 18 ve 24 aylık kontrollerinde klinik ve radyografik olumsuz bir semptom gözlenmedi.

$\mathrm{Bu}$ olgu raporunda çoklu travma olgularında tedavi planlaması ve takibinin büyük öneme sahip olduğu vurgulanmıştır.

Anahtar sözcükler: Anterior çapraz kapanış, intrüzyon, ekstrüzyon

\section{ABSTRACT}

The purpose of this case report is to present a case of a patient who had anterior cross-bite and suffered from intrusion and extrusion of maxillary central incisors at the same trauma.

An 8-year-old girl was referred to Gazi University Faculty of Dentistry, Department of Pediatric Dentistry, who suffered from slide accident within 1 hours. During clinical examination intrusion of maxillary right central incisor(\#11), extrusion of maxillary left central incisor(\#21) and anterior crossbite were detected. While considering the multiple trauma, it was decided that repositioning of \#21 and waiting for the spontaneous re-eruption of \#11 that has open apices, would be the best choice. In addition, teeth were splinted with non-rigid splint. At the 6th month follow-up, loss of vitality and discoloration of \#21 was determined. Apexification was indicated. The patient was followed-up for 24 months.

The intruded tooth was re-erupted spontaneously in 12 months. Moreover anterior cross-bite was also corrected without any intervention. Apexification of the \#21 was shown no symptoms radiographically or clinically throughout the 12th, 18th and 24th month follow-ups.

This case report features that the treatment planning of multiple trauma patients and follow-ups should be highlighted to have great importance.

Key words: Anterior cross-bite, intrusion, extrusion

\footnotetext{
*Gazi Üniversitesi Diş Hekimliği Fakültesi Pedodonti AD.

${ }^{\ddagger}$ Bu olgu; 18. International Associaton of Dental Traumatology (IADT) World Congress,

İstanbul-Türkiye, 19-21 Haziran 2014 tarihinde poster olarak tebliğ edilmiştir
} 


\section{GİRİS}

Dental travmalar, periodontal ve dental dokularda ciddi hasarlar meydana getirebilen sık görülen yaralanmalardandır ${ }^{1,2}$. Çocuklar, yetersiz fiziksel ve bilişsel gelişime bağlı olarak travmaya eğilimlidirler ${ }^{3,4}$. Çocukların ağız ve yüz yapılarına gelen travmalar hem çocuklar ve hem de ebeveynleri için ciddi fiziksel, tıbbi, estetik ve psikolojik sonuçlar doğurabilen önemli bir sorundur ${ }^{5-7}$.

Travmalar genellikle 1 veya 2 dişi kapsamakta ve özelliklede üst çene santral keserleri etkilemekte$\operatorname{dir}^{2,7,8}$. Dişlerin normal pozisyonlarına göre yer değiştirmeleri lüksasyon yaralanmaları olarak adlandırılır. Lüksasyon yaralanmalarında, dişlerin normal konumlarından uzaklaşmasına bağı olarak pulpa ve periodontal ligament için ciddi sorunlar oluşabilmektedir. Bu yaralanma yer değiştirme yönüne göre intrüzyon, lateral lüksasyon ve ekstrüzyon gibi alt gruplara ayrılmaktadır ${ }^{9}$. İntrüzyon dişin apikal yönde yer değiştirmesi olarak tanımlanmaktadır. İntrüze diş klinik olarak dişi çevreleyen dokular arasında tamamen kaybolabilir veya klinik kronu travma görmemiş komşu dişten daha kısa olacak şekilde insizal kısmı görünür şekilde kalabilir $^{1,10-12}$. Bu travma tipine genellikle alveol kemiği de eşlik etmektedir. Peridontal ligamentde ve sementte yaygın harabiyet nedeni ile prognozunun zayıf olduğu belirtilmektedir ${ }^{2,10,12}$. Daimi dentisyonda intrüzyon görülme sıklığı \%0,3-1,9 arasında; en yük- sek insidansı ise 6-12 yaş aralığında göstermektedir ${ }^{1,6}$. Ekstrüzyon ise dişin kısmı olarak soketinden çıkması olarak tanımlanır. Bu yaralanmada periodontal ligamentte kısmı yada tam ayrılma görülebilmektedir ${ }^{13}$. Diş uzamış görünür, aşırı derecede hareketlidir ve dişeti oluğunda kanama vardır ${ }^{14}$.

Literatürde, artmış over-jet, açık kapanış, mesiodens varlığı ve yetersiz dudak kapanışı travma için risk faktörü olarak gösterilmektedir ${ }^{7,15,16}$. Viegas ve ark. $^{7}$ ise anterior çapraz kapanışın travma için koruyucu faktör olduğunu belirtmektedir. Bu olgu raporunda; anterior çapraz kapanışı bulunan hastada intrüzyon ve ekstrüzyonun birlikte görüldüğü travma olgusunun tedavisi anlatılmaktadır.

\section{OLGU RAPORU}

8 yaşında kız hasta, Gazi Üniversitesi Diş Hekimliği Fakültesi Pedodonti Kliniği'ne kaydıraktan düşmeye bağlı travma hikayesi ile, travmadan 2 saat sonra başvurmuştur. Alınan anamnezde hastanın herhangi bir genel sağlık sorunu olmadığı saptandı. Ağız dışı muayenesinde dudakta laserasyon görüldü. Ağız içi muayenesinde 11 numaralı dişte $2 \mathrm{~mm}$ intrüzyon, 21 numaralı dişte ekstrüzyon ve 2. derece mobilite tespit edildi (Resim 1). Radyografik muayenede alveolar kırık saptanmadı (Resim 2).

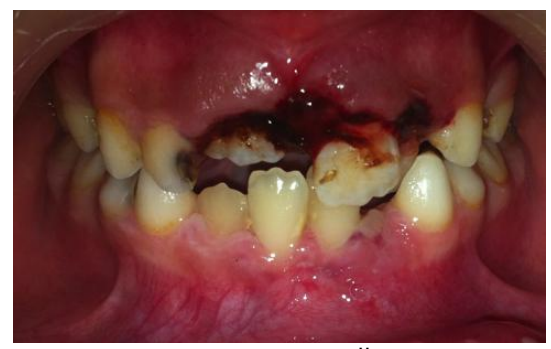

Resim 1. Travma sonrası ağız içi görünüm. 11 numaralı diş intrüze, 21 numaralı diş ekstrüze

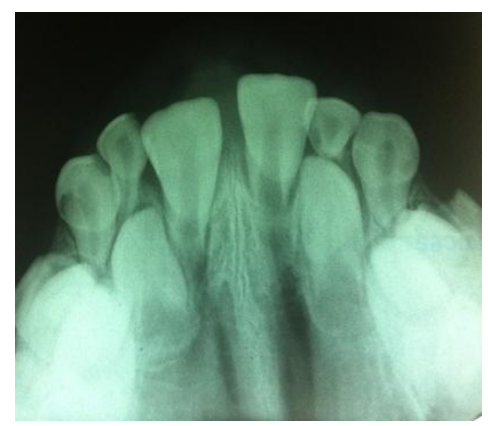

Resim 2. Travma sonrası radyografik görünüm

Tedavi planlamasında öncelikle dudaktaki kanama odakları temizlendi. 21 numaralı diş, parmak basısı ile yerine getirilerek 53-52-21-63 numaralı dişlerden destek alınarak tam yuvarlak $0.5 \mathrm{~mm}$ 'lik ortodontik tel ve Tetric N-Ceram $\AA$ (Ivoclar Vivadent, Liechtenstein) kompozit ile yarı esnek splint yapıldı. Travmaya bağlı mobilitesi artan 62 numaralı dişin çekimi gerçekleştirildi. Anamnezinde travma öncesi çapraz kapanışta bulunduğu belirtilen 11 numaralı dişin ise spontan re-erüpsiyonunun beklenmesine karar verildi. 1. hafta kontrolünde 21 numaralı dişin mobilitesinin azaldığı ve 11 ile 21 nolu dişlerin vital olduğu belirlendi.

3. hafta kontrolünde mobilitenin sonlanması ile beraber splint sökümü gerçekleştirildi. Vitalite testinde 11 ve 21 numaralı dişler pozitif sonuç gösterdi. 3. ay kontrolünde 11 numaralı dişin bir miktar reerüpsiyonu gözlendi. 11 ve 21 numaralı dişlerin vital olduğu tesbit edildi. 
6. ay kontrolünde 11 numaralı dişin bir miktar daha re-erüpsiyonu gözlendi ve spontan olarak anterior çapraz kapanış pozisyonundan uzaklaştığı tesbit edildi. 21 numaralı dişte görülen renkleşme, vitalite kaybı ve periapikal radyografide tesbit edilen lamina dura kaybı sonucu dişe apeksifikasyon tedavisine başlandı. 21 numaralı dişin 2 haftalık kalsiyum hidroksit (Kalsin, Spot Diş Deposu, Türkiye) ile tedavisi sonrasında apikal bariyer $3 \mathrm{~mm}$ Mineral Trioksit Agregat (MTA)(Pro-Root MTA, Dentsply, Germany) ile oluşturuldu (Resim 3). 48 saat sonra kanal tedavisi AH 26 (Dentsply, Germany) ve Gutta Perka (PearlDent, Korea) ile tamamlandı.

12. ay kontrolünde 11 numaralı dişin tamamen re-erüpsiyonu ile çapraz kapanıştan çıktığı ve 21 numaralı dişte herhangi bulgu olmadığı görüldü (Resim 4). 18. ve 24. ay kontrollerinde klinik ve radyografik herhangi bir semptom saptanmadı (Resim 5, 6).

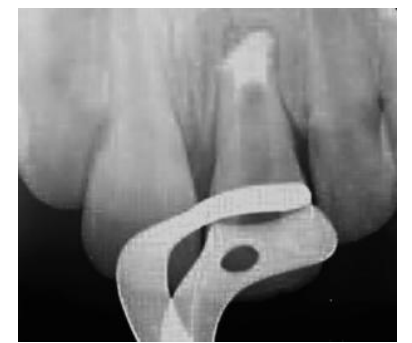

Resim 3. MTA ile oluşturulan $3 \mathrm{~mm}$ apikal bariyerin görünümü

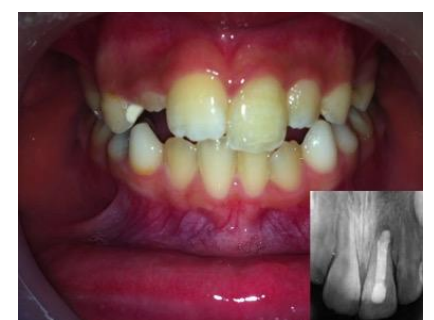

Resim 4. 12. ay kontrol görüntüsü

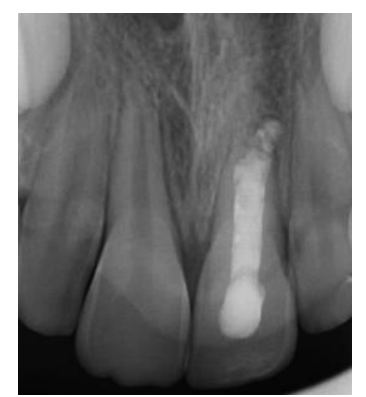

Resim 5. 24. ay kontrolünde radyografik görünüm

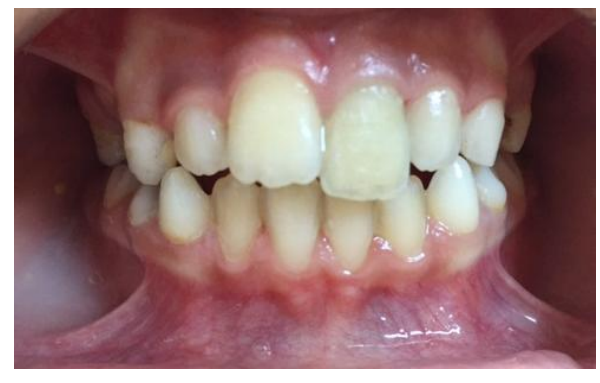

Resim 6. 24. ay kontrolünde ağız içi görünüm

\section{TARTIŞMA}

Dentoalveoler travmaların tedavi planlamasında; hastanın yaşı, kooperasyonu, travma tipi, travma ile tedaviye başlama arasında geçen süre, dentisyon tipi, alveoler kemikte kırık varlığı ve kök gelişim derecesi gibi faktörler büyük öneme sahiptir ${ }^{17}$. Bu olguda, hastanın yaşı, kooperasyonu, karma dentisyonda oluşu, alveoler proçeste kırık olmaması ve travmaya uğrayan dişlerin apekslerinin açık olması bir avantaj oluşturmaktadır. Ancak intrüzyon ve ekstrüzyon travmalarını birlikte içeren çoklu travmatik yaralanma olması ve hastada anterior çapraz kapanış bulunması tedavi planlamasını zorlaştırmıştır. Anterior çapraz kapanışın travma için koruyucu faktör olduğu belirtilmiştir ${ }^{7}$. Ancak bu olguda 11 numaralı dişin anterior çapraz kapanışta bulunmasının çoklu travmanın oluşumuna uygun ortam sağladığı düşünülmektedir. 11 numaralı dişte anterior çapraz kapanışa bağlı intrüzyon oluşurken normal pozisyondaki 21 numaralı dişte ekstrüzyon görülmüştür. Literatür taramasında aynı olguda intrüzyon ve ekztrüzyonun birlikte oluştuğu travmaya rastlanmamıştır.

Daimi keser dişlerde oluşan intrüzyonun acil tedavisi üç seçenekten oluşmaktadır; dişin eski konumuna getirilmesi, spontan re-erüpsiyonun beklenmesi, ortodontik sürdürme ${ }^{18}$. Bu olguda intrüze dişin travma öncesinde ön çapraz kapanışta bulunması nedeni ile dişin eski konumuna getirilmesinin uygun olmayacağı, dişin açık apeksli olması nedeni ile sponton re-erüpsüyon için beklenmesine karar verildi. Andreasen ve ark. ${ }^{19}$; kök gelişimi tamamlanmamış intrüze dişlerde spontan re-erüpsiyonun beklenmesini, kök gelişimi tamamlanmış olan 12-17 yaşları arasındaki hastalarda dahi spontan re-erüpsiyonun bir süre gözlemlenmesi gerektiğini belirtmişlerdir. Wigen ve ark. ${ }^{20}$ da 6-12 yaş aralığında dişlerin kendiliğinden sürmesinin beklenmesi gerektiğini bildirmişlerdir. Olgunun 3. ay kontrolünde

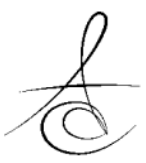


bir miktar re-erüpsüyon gözlenirken, 12 . ayın sonunda tamamen re-erüpsüyonun tamamlandığı ve dil itiminin de etkisi ile çapraz kapanıştan uzaklaştığı belirlenmiştir.

Daimi keser dişlerin ekstrüzyon olgularında genellikle tedavi planlaması dişin eski konumuna getirilmesi ve 2-3 hafta yarı esnek splint ile sabitlenmesidir $^{13,21,22}$. Diangelis ve ark. ${ }^{14}$ International Associaton of Dental Traumatology (IADT)'nin yönergesinde kök gelişimini tamamlamamış dişlerde pulpa, nekroz bulgularını gösterdiği zaman kök kanal tedavisine başlanması gerektiğini belirtmektedir. Bu olguda ekstrüze 21 numaralı diş parmak basısı ile eski konumu getirilmiş ve yarı esnek splint ile 3 hafta sabitlenmiştir. Dişin kök gelişimini tamamlamaması ve vitalite testine pozitif cevap vermesi nedeni ile pulpal durum takip edilmiştir. Kontrollerinde vital olduğu belirlenen 21 nolu dişte 6 . ayda renk değişimi gözlenmiş ve vitalite testinde negatif cevap alınmıştır. Ekstrüzyon olgularında periodontal ligamentlerdeki hasara bağlı olarak pulpa nekrozu görülme intimalinin yüksek olduğu belirtilmektedir ${ }^{13,14}$. Periodontal liflerin kopması yada apikal nöromusküler demetin zedelenmesi ile pulpal kan dolaşımı etkileneceği ve liflerin esnediği durumlarda pulpal nekrozun daha geç oluşabileceği bildirilmektedir ${ }^{13}$. Bu olgudaki ektrüzyonda pulpal hasar 6 . ayda oluşmuştur.

Kök gelişimi tamamlanmamış dişlerde kanal tedavisi sonrası apikal tıkaç oluşturmak oldukça zordur. Tedavi için öncelikli seçenek kalsiyum hidroksit ile apeksifikasyondur ${ }^{23}$. Bu yöntem uzun yıllardır kullanılmasına rağmen; apekste sert doku bariyeri oluşturulmasının uzun zaman alması, koronal ve apikal bariyerlerin eksik oluşarak sızıntıya sebep olabilmesi, dentin yapısında kalsiyum hidroksite bağlı fiziksel değişiklikler meydana getirebilmesi gibi dezavantajları da bulunmaktadır ${ }^{24}$. Alternatif tedavi yöntemi ise son yıllarda sıklıkla kullanılan Mineral Trioxide Aggregate (MTA) ile tek aşamalı apikal tıkaç oluşturulması tekniğidir. Yapılan bir çok çalışmada MTA'nın, sert doku oluşumu uyarması, biyouyumlu yapısı ve mekanik özellikleri ile apeksifikasyon için uygun bir materyal olduğu gösterilmiştir ${ }^{23,25,26}$. Bu olguda 2 hafta kalsiyum hidroksit ile kanal içi iyileşme sağlandıktan sonra $3 \mathrm{~mm}$ MTA ile apikal tıkaç oluşturularak kök-kanal tedavisi sonlandırımıştır. Hastanın 12, 18 ve 24 aylık kontrollerinde herhangi bir semptoma rastlanmamıştır.

\section{SONUÇ}

Travma acil müdahale edilmesi gereken ve diş hekimlerinin yeterli bilgiye sahip olmasını gerektiren önemli bir konudur. Özellikle intrüzyon ve ekstrüzyonun birlikte görüldüğü çoklu travmalar tedavi planlamasını zorlaştırabilmektedir. Bu olguda anterior çapraz kapanışta bulunan intrüze dişin dil itimi ile re-erüpte olduğu ve ekstrüze dişin ise apeksifikasyonun başarı ile tamamlandığı görülmüştür. Bu olgu raporunda travma olgularında tedavi planlaması ve yönetiminin büyük öneme sahip olduğu vurgulanmıştır.

\section{KAYNAKLAR}

1. Andreasen JO, Bakland LK, Matras RC, Andreasen FM. Traumatic intrusion of permanent teeth. Part 1. An epidemiological study of 216 intruded permanent teeth. Dent Traumatol 2006;22:83-9.

2. Şaroğlu I, Sonmez H. The prevalence of traumatic injuries treated in the pedodontic clinic of Ankara University, Turkey, during 18 months. Dent Traumatol 2002;18:299-303.

3. Canoglu E, Akcan CA, Baharoglu E, Gungor HC, Cehreli ZC. Unusual ectopic eruption of a permanent central incisor following an intrusion injury to the primary tooth. J Can Dent Assoc 2008;74:723-6.

4. Harrington MS, Eberhart AB, Knapp JF. Dentofacial trauma in children. ASDC J Dent Child 1988;55:334-8.

5. Rocha MJ, Cardoso M. Survival analysis of endodontically treated traumatized primary teeth. Dent Traumatol 2007;23:340-7.

6. Andreasen JO, Andreasen FM, Andersson L. Textbook and color atlas of traumatic Injuries to the Teeth. 4th ed. Copenhagen; Munksgaard: 2007. p. 151-77.

7. Viegas CM, Scarpelli AC, Carvalho AC, Ferreira FM, Pordeus IA, Paiva SM. Predisposing factors for traumatic dental injuries in brazilian preschool children. Eur J Peadiatr Dent 2010;11:59-65.

8. Ünal $M$, Tuğut $F$, Demir $H$. Travmatik komplike kuron kırığı ve lateral lüksasyon tedavisinin üç yıllık takibi: olgu raporu. Atatürk Üni Diş Hek Fak Derg 2013;23:380-4.

9. Belmonte FM, Macedo CR, Day PF, Saconato $H$, Fernandes Moça Trevisani V. Interventions for treating traumatised permanent front teeth:

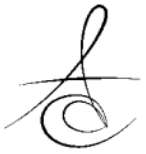


luxated (dislodged) teeth. Cochrane Database Syst Rev 2013;3:CD006203

10. Koch G, Poulsen S. Pediatric dentistry a clinical approach. 2nd ed. Copenhagen; Wiley-Blackwell: 2009. p. 264-297.

11. Gomes AC, Messias LPDA, Delbem ACB, Cunha RF. Developmental disturbance of an unerupted permanent incisor due to trauma to its predecessor. J Can Dent Assoc 2010;76:a57.

12. Pinkham JR, Casamassimo PS, McTigue DJ, Fields HW, Nowak AJ. Pediatric dentistry: Infancy through adolescence. 4th ed. St. Louis; Elsevier Saunders: 2005. p. 593-607.

13. Hermann NV, Lauridsen E, Ahrensburg SS, Gerds $\mathrm{TA}$, Andreasen JO. Periodontal healing complications following extrusive and lateral luxation in the permanent dentition: a longitudinal cohort study. Dent Traumatol 2012;28:394-402.

14. Diangelis AJ, Andreasen JO, Ebeleseder KA, Kenny DJ, Trope $M$, Sigurdsson A, Andersson L, Bourguignon $C$, Flores $M T$, Hicks ML, Lenzi AR, Malmgren B, Moule AJ, Pohl Y, Tsukiboshi M. International Association of Dental Traumatology Guidelines for The Management of Traumatic Dental Injuries: 1. Fractures and luxations of permanent teeth. Dent Traumatol 2012;28:2-12.

15. Alaçam A, Bani M. Mesiodens as a risk factor in treatment of trauma cases. Dent Traumatol 2009;25:e25-31.

16. Gupta S, Kumar-Jindal S, Bansal M, Singla A. Prevalence of traumatic dental injuries and role of incisal overjet and inadequate lip coverage as risk factors among 4-15 years old government school children in Baddi-Barotiwala Area, Himachal Pradesh, India. Med Oral Patol Oral Cir Bucal 2011;16:e960-5.

17. Canoglu E, Akcan CA, Baharoglu E, Gungor HC, Cehreli ZC. Unusual ectopic eruption of a permanent central incisor following an intrusion injury to the primary tooth. J Can Dent Assoc 2008;74:723-6.

18. Tsilingaridis G, Malmgren B, Andreasen JO, Malmgren O. Intrusive luxation of 60 permanent incisors: a retrospective study of treatment and outcome. Dent Traumatol 2012;28:416-22.

19. Andreasen JO, Bakland LK, Andreasen FM. Traumatic intrusion of permanent teeth. Part 3. A clinical study of the effect of treatment variables such as treatment delay, method of repositioning, type of splint, length of splinting and antibiotics on 140 teeth. Dent Traumatol 2006;22:99-111.

20. Wigen TI, Agnalt R, Jacobsen I. Intrusive luxation of permanent incisors in Norwegians aged 6-17 years: a retrospective study of treatment and outcome. Dent Traumatol 2008;24:612-8.

21. Lauridsen E, Hermann NV, Gerds TA, Ahrensburg SS, Kreiborg S, Andreasen JO. Combination injuries 3. The risk of pulp necrosis in permanent teeth with extrusion or lateral luxation and concomitant crown fractures without pulp exposure. Dent Traumatol 2012;28:379-85.

22. Lee R, Barrett EJ, Kenny DJ. Clinical outcomes for permanent incisor luxations in a pediatric population. II. Extrusions. Dent Traumatol 2003;19:274-9.

23. Bakland LK, Andreasen JO. Will mineral trioxide aggregate replace calcium hydroxide in treating pulpal and periodontal healing complications subsequent to dental trauma? A review. Dent Traumatol 2012;28:25-32.

24. Akin A, Uysal S, Cehreli C. Segmental alveolar process fracture involving primary incisors: treatment and 24-month follow up. Dent Traumatol 2011;27:63-6.

25. Damle SG, Bhattal H, Loomba A. Apexification of anterior teeth: a comparative evaluation of mineral trioxide aggregate and calcium hydroxide paste. J Clin Pediatr Dent 2012;36:263-8.

26. Maroto $M$, Barbería $E$, Planells $P$, Vera V. Treatment of a non-vital immature incisor with mineral trioxide aggregate (MTA). Dent Traumatol 2003;19:165-9
Yazışma Adresi
Dt. Esra Karaalioğlu
Gazi Üniveristesi Diş Hekimliği Fakültesi
Pedodonti Anabilim Dalı Emek, Ankara, Türkiye
TIf: 03122034090
Fax: 03122239226
e-mail: esrakaraalioglu@hotmail.com 